nhiễm, CTYT thông thường,.. và quá trình vân chuyển CTYT được cải thiện rõ rệt sau 4 tuần thử nghiệm.

\section{KẾT LUÂ̂N VÀ KIẾN NGH!}

Kết luận: Bộ công cụ giám sát chủ động chất thải y tế có hiệu quả trong cải thiện tỷ lệ đạt các tiêu chí đánh giá trong công tác phân loại, thu gom và vận chuyển chất thải y tế tại bệnh viện đa khoa khu vực Phúc Yên và bệnh viện đa khoa tỉnh Thanh Hóa. Tỷ lệ đạt các tiêu chí đánh giá về dụng cụ, thiết bị lưu chứa chất thải y tế, phân loại, thu gom và vận chuyển chất thải y tế tăng với đa số các tiêu chí đạt trên $90 \%$ ở tuần thứ 4 sau thử nghiệm bộ công cụ giám sát chủ động chất thải y tế.

Kiến nghị: Cần tiếp tục duy trì áp dụng mô hình và có chỉnh sửa, điều chỉnh cho phù thực tiễn hoạt động khám chữa bệnh và mức độ phát thải của bệnh viện để có thể áp dụng rộng rãi hơn.

\section{TÀI LIÊU THAM KHẢO}

1. Bộ $Y$ tế. Điểm tin y tế ngày $15 / 12 / 2017$. Tại: httips://www.moh.gov.vn/diem-tin-y-te//asset_publisher/ sqTagDPp4aRX/content/-iem-tiny-te-ngay-15-12-2017?inheritRedirect=false.

2. Chartier $\mathbf{Y}$ et al. Safe management of wastes from health-care activities. World Health Organization. 2014.

3. Tạp chí môi trường. Các bệnh viện thực hiện phân loại rác thải tai nguồn 2019. Tại: http://tapchimoitruong.vn/pages/article.aspx?item $=\mathrm{C} \% \mathrm{C} 3 \% \mathrm{~A} 1 \mathrm{c}-\mathrm{b} \% \mathrm{E} 1 \% \mathrm{BB} \% 87 \mathrm{nh}-$ vi\%E1\%BB\% 87 n-th\%E1\%BB\%B1chi\%E1\%BB\%87n-ph\%C3\%A2n-lo\%E1\%BA\%A1ir\%C3\%A1c-th\%E1\%BA\%A3i-t\%E1\%BA\%A1ingu $\%$ E1\%BB\%93n-50659.

4. Bộ Y tế. Sổ tay hướng dẩn quản lý chất thải y tế trong bệnh viện. Nhà xuất bản Y học Hà Nội. 2015.

\title{
TĂNG HUYẾT ÁP ÁO CHOÀNG TRẮNG VÀ TĂNG HUYẾT ÁP ẨN GIẤU Ở BÊ̂NH NHÂN ĐÁI THÁO ĐƯờNG TÍP 2: XUẤT Độ VÀ YẾU TỐ LIÊN QUAN
}

TÓM TĂT

Mở đâu: Tăng huyết áp (THA) là bệnh lý đi kèm thường gặp nhất trên người bệnh đái tháo đường (ĐTĐ). Các thể THA như THA áo choàng trắng và THA ẩn giấu có tỉ lệ khá cao đối với người bệnh ĐTĐ, đặc biệt là ĐTÐ típ 2. Mục tiêu: Xác định tỉ lệ và các yểu tố liên quan của THA áo choàng trắng và THA ẩn giấu trên người bệnh đái tháo đường típ 2 . Đối tượng và phương pháp nghiên cứu: Nghiên cứu mô tả cắt ngang trên 306 người bệnh tại phòng khám Nội Tiết ngoai trú, Bệnh viên Nhân Dân Gia Đinh TP.Hồ Chí Minh. Kết quả: 24,5\% đối tượng có THA ẩn giấu, $30,1 \%$ có THA áo choàng trắng. Các yếu tố như đố tuổi, thời gian mắc ĐTĐ, tiền sử gia đinnh THA, ĐTĐ, hút thuốc lá, uống rượu bia, ăn măn và tâp thể duc có mối liên quan chung với các thể THA. Kết luận: Kết quả nghiên cứu nhắc lai việc ứng dung đo hưyết áp liên tục 24 giờ trong xác định các thể THA, góp phân phòng ngừa các biến cố bất lợi do THA gây ra trên người bệnh ĐTĐ típ 2.

Tư khóa: THA áo choàng trắng, THA ẩn giấu, ĐTĐ típ 2, yếu tố nguy cơ

\section{SUMMARY}

\footnotetext{
*Bệnh viện đa khoa tỉnh Bình Dương

**Đai hoc Y dước thành phố Hồ Chí Minh

Chịu trách nhiệm chính: Nguyễn Văn Lực

Email: nguyenvanlucphoto@gmail.com

Ngày nhận bài: 18.12.2020

Ngày phản biện khoa học: 22.01.2021

Ngày duyệt bài: 01.2.2021
}

\section{WHITE-COAT HYPERTENSION AND MASKED HYPERTENSION IN DIABETIC TYPE 2 PATIENTS: PREVALENCE AND THEIR RELATED FACTORS}

Introduction: Hypertension is the most common comorbidity of diabetes. White-coat and masked hypertension are high prevalence hypertension phenotypes, especially in type 2 diabetic patients. Objectives: To evaluate the prevalence and related factors of white-coat and masked hypertension in type 2 diabetic patients. Method: A cross-sectional study was conducted in 306 diabetic type 2 patients in Nhan Dan Gia Dinh hospital - Ho Chi Minh city. Results: The prevalence of white-coat and masked hypertension were $30.1 \%$ and $24.5 \%$, respectively. Aqe, family history of hypertension, diabetes, smoking, drinking, salt consuming, and physical activites were associated with hypertension phenotypes. Conclusion: Data remind us of application ambulatory blood pressure monitoring to identify hypertension phenotypes for prevention adverse events in type 2 diabeticsubjects.

Keyword: White-coat hypertension, masked hypertension, diabetes type 2 , related factors

\section{I. ĐĂT VẤN ĐỀ}

Tăng huyết áp (THA) và đái tháo đường (ĐTÐ) là hai bệnh lý mạn tính đang gia tăng với tốc độ nhanh chóng trên toàn cầu. Sự tác động cộng hợp giữa THA và ĐTĐ gây nhiều hệ quả nghiêm trọng đến hệ thống tim mạch. Bệnh nhân ĐTÐ kèm THA tắng nguy cơ tim mạch gấp 
2 - 4 lần so với người ĐTĐ không THA. Nghiên cứu Framingham cũng đã chứng minh rằng $\mathrm{THA}$ kết hợp ĐTÐ làm tăng $30 \%$ nguy cơ tử vong chung và $25 \%$ các biến cố tim mạch. Vì vậy việc chẩn đoán và điều trị THA trên bệnh nhân ĐTĐ cần phải nghiêm ngặt hơn.

Việc đánh giá THA dựa trên huyết áp khi thăm khám lâm sàng thổng thường được ghi nhận là chưa phản ánh chính xác được giá trị huyết áp thật sự của hơn $50 \%$ các trường hợp được đo ${ }^{(6)}$. Theo ghi nhận, huyết áp của một người có xu hướng dao động theo chu kỳ ngày và đêm, tăng giảm tùy thuộc vào hoàn cảnh hiện tại như nghỉ ngơi, lao động thể lực hay trí óc, chịu ảnh hưởng bởi yếu tố tâm lý, môi trường. Do đó, việc chẩn đoán và điều trị THA còn nhiều vấn đề cần làm rõ. Việc áp dụng kỹ thuật đo huyết áp liên tục 24 giờ giúp giải quyết được sự thay đổi của huyết áp. Với kỹ thuật này, nhà lâm sàng có thể chẩn đoán tăng huyết áp áo choàng trắng, THA thật sự, THA ẩn giấu hay không THA. Trong các hướng dẫn điều trị THA Anh Quốc, Canada, Châu Âu... đã đưa huyết áp liên tục 24 giờ vào chẩn đoán các thể THA này ${ }^{(5)}$.

Các nghiên cứu gần đây cho thấy rằng cả THA áo choàng trắng lẫn THA ẩn giấu đều có liên quan với sự gia tăng các biến cố về tim mạch, đặc biệt ở bệnh nhân ĐTĐ. Tuy nhiên, hầu hết các thể THA này đều ít được chú ý khi thămm khám thông thường. Việc này vô tình làm diễn tiến THA gây hại đến cớ thể nhưng không được đánh giá và điều trị chính xác. Các nghiên cứu về ứng dụng huyết áp liên tục 24 giờ để đánh giá các thể THA trên thế giới đã được ghi nhận, song tại Việt Nam còn hạn chế. Việc ứng dụng hiện nay tại Việt Nam chủ yếu tại các trung tâm tim mạch lớn, do đó, tỉ lệ THA áo choàng trắng và THA ẩn giấu trên dân số Việt Nam chưa được đánh giá một cách đầy đủ. Nghiên cứu được tiến hành nhằm đánh giá tî lệ THA áo choàng trắng và THA ẩn giấu, xác định các yếu tố liên quan để từ đó có cái nhìn tổng quát và là cơ sở điêu trị cho người bệnh ĐTĐ típ 2.

\section{II. ĐỐI TƯợNG VÀ PHƯƠNG PHÁP NGHIÊN CỨU}

1. Đối tượng nghiên cứu: Tất cả người bệnh đang điều trị hay mới chẩn đoán ĐTĐ típ 2 theo tiêu chuẩn chẩn đoán của Hiệp hội ĐTĐ Hoa Kì năm 2017, trên 18 tuổi, không đang uống thuốc hạ áp được chọn ngẫu nhiên hệ thống dựa trên ước lượng số lượt bệnh đến khám trung bình mỗi ngày. Người bệnh bị loại trừ khỏi nghiên cứu khi ghi nhận ĐTĐ típ 1, ĐTÐ thai kỳ, bệnh nhân mắc các bệnh lý cấp tính như: có sốt (trên $38^{\circ} \mathrm{C}$ ), nhiễm trùng đường tiểu, đang điều trị với cimetidine; có hoạt động thể lực gắng sức trong vòng 24 giờ; đang hành kinh; nước tiểu dưới $500 \mathrm{ml} / 24$ giờ; có tiền căn đột quy, suy tim phân suất tống máu giảm (EF dưới $50 \%$ ), suy thận mạn nồng độ creatinine huyết thanh trên $2 \mathrm{mg} / \mathrm{dl}$, tăng huyết áp đang điều trị.

2. Đánh giá huyết áp liên tục 24 giờ. Người bệnh được đo huyết áp liên tục 24 giờ bằng máy MICROLIFE 24H WATCHBP $\mathrm{O} 3$, được kiểm nghiệm qua ba tiêu chuẩn quốc tế: Hiệp hội Tăng huyết áp Anh, Châu Âu và Hiệp hội Dụng cụ Y khoa. Máy đo theo phương pháp dao động mạch, nhỏ, băng từ ghi lại kêt quả trong 24 giờ. Màn hình hiển thị huyết áp tâm thu, huyết áp tâm trương, tần số tim. Máy đo tự động bơm căng túi hơi và xả hơi từ từ 2$3 \mathrm{mmHg}$. Băng quấn: $25 \times 35 \mathrm{~cm}$. Phần mềm AccuWinPro v3: thời gian theo dõi huyết áp 24 giờ, thời gian ngày từ 6 giờ đến 22 giờ (môi 30 phút đo 1 lần) và thời gian đêm từ 22 giờ đến 6 giờ (60 phút đo 1 lần).

Dựa trên các giá trị huyết áp, nghiên cứu chia làm 4 nhóm:

- HA được xem là bình thường thật sự khi: HA tại phòng khám dưới $140 / 90 \mathrm{mmHg}$ và HALT 24 giờ có: HA ban ngày dưới 135/ $85 \mathrm{mmHg}$ và $\mathrm{HA} 24$ giờ dưới 130/80 mmHg.

- THA thật sự được xác định khi:

+ HA tại phòng khám $\geq 140 / 90 \mathrm{mmHg}$ và

+ HALT24 giờ có: HA ban ngày $\geq 135 / 85 \mathrm{mmHg}$ và/ hoặc HA 24 giờ $\geq 130 / 80 \mathrm{mmHg}$.

- THA ẩn giấu

- Huyết áp đo ở phòng khám dưới 140/90mmHg và HALT 24 giờ: HA ban ngày $\geq 135 / 85 \mathrm{mmHg}$ và hoặc HA 24 giờ $\geq 130 / 80 \mathrm{mmHg}$.

- THA áo choàng trắng: được xác định trên NB không được điều trị THA khi HA đo tại phòng khám $\geq 140 / 90 \mathrm{mmHg}$ và HALT 24 giờ có $\mathrm{HA}$ ban ngày dưới $135 / 85 \mathrm{mmHg}$ và $\mathrm{HA} 24$ giờ dưới $130 / 80 \mathrm{mmHg}$

3. Phương pháp thu thập dữ liệu: lấy mẫu ngẫu nhiên hệ thống, người bệnh thỏa mãn các tiêu chí chọn mẫu và tiêu chí loại trừ. Mẫu nghiên cứu được gắn huyết áp liên tục 24 giờ, nhân viên y tế hướng dẫn người bệnh tuân thư và ghi nhận các thông tin liên quan nghiên cứu.

4.Phương pháp xử lý dữ liệu. Nhập liệu trên Microsoft Excel, sử dụng phần mềm Stata 14.0 để phân tích. Phép kiểm $\chi 2$ đánh giá mối liên quan giữa các thể THA với các biến số định tính như giới tính, hút thuốc lá, uống rượu, tiền sử gia đình,... Phép kiểm ANOVA, post-hoc Tukey's test đánh giá mối liên quan giữa các thể 
THA với biến số định lượng; phép kiểm KruskalWallis, post-hoc Dunn's test được sử dụng khi không thỏa điều kiện đánh giá bởi ANOVA. Giá trị $p<0,05$ được đánh giá là có ý nghĩa về mặt thống kê.

\section{KẾT QUẢ NGHIÊN CỨU}

Nghiên cứu ghi nhận dữ liệu trên 306 người bênh đến khám ngoại trú tại phòng khám Nội Tiết, Bểnh viên Nhân Dân Gia Đinh TP.Hồ Chí Minh.

1. Đặc điểm mẫu nghiên cứu. Tỉ lệ giới tính trong nghiên cứu tương đối đồng đều (48,5\% ở nam giới và $51,5 \%$ ở nữ giới). Độ tuổi trung bình là 53,8 \pm 9,8 tuổi. Có 51,9\% mẫu nghiên cứu có tiền sử gia đình bị THA, tiền sử ĐTĐ ghi nhận ở $60,5 \%$ người bệnh. Tỉ lệ hút thuốc lá là $23,6 \%$, uống rượu bia là $8,1 \%$, ăn mặn là $47,8 \%$ và tập thể dục là $45,5 \%$. Thời gian mắc bênh đái tháo đường trung bình là 5,27 $\pm 4,54$ năm, cao nhất 30 năm và thấp nhất là 1 năm.

\begin{tabular}{|c|c|c|}
\hline Các thế THA & Tân số & Tỉ lê (\%) \\
\hline Không THA & 139 & 45,4 \\
\hline THA áo choàng trằng & 92 & 30,1 \\
\hline THA ấn giấu & 75 & 24,5 \\
\hline
\end{tabular}

3. Các yếu tố liên quan đến tăng huyết áp

\section{Bảng 2: Đặc điểm nhân trắc của mẫu nghiên cứu (n=306)}

\begin{tabular}{|c|c|c|c|c|c|c|c|}
\hline & \multicolumn{3}{|c|}{ Phân loại tăng huyết áp } & \multirow[b]{2}{*}{$\mathbf{p}_{\mathbf{1}}$} & \multirow[b]{2}{*}{$\mathbf{p}_{2}$} & \multirow[b]{2}{*}{ p3 } & \multirow[b]{2}{*}{ p4 } \\
\hline & $\begin{array}{c}\text { Không THA } \\
(n=139)\end{array}$ & $\begin{array}{c}\text { THA } \\
\text { áo choàng trắng } \\
(\mathrm{n}=92)\end{array}$ & $\begin{array}{c}\text { THA } \\
\text { ẩn giấu } \\
(\mathrm{n}=75)\end{array}$ & & & & \\
\hline Tuối & $52,2 \pm 9,9$ & $51,7 \pm 8,6$ & $59,3 \pm 9,1$ & $<0,001$ & 0,910 & $<0,001$ & $<0,001$ \\
\hline BMI $\left(\mathrm{kg} / \mathrm{m}^{2}\right)$ & $23,2 \pm 2,7$ & $23,2 \pm 2,7$ & $23,3 \pm 3,2$ & 0,923 & 1,000 & 0,927 & 0,938 \\
\hline \multicolumn{8}{|c|}{ Giới tính } \\
\hline$\frac{\mathrm{Nam}}{\mathrm{N} \tilde{r}}$ & $\begin{array}{l}73(52,5) \\
66(47,5)\end{array}$ & $\begin{array}{l}26(28,3) \\
66(71,7)\end{array}$ & $\begin{array}{l}46(61,3) \\
29(38,7)\end{array}$ & $<0,001$ & $<0,001$ & 0,216 & $<0,001$ \\
\hline
\end{tabular}

p1: đánh giá khác biệt chung, p2: đánh giá khác biệt giữa THA áo choàng trắng với không THA, $\mathrm{p}_{3}$ : đánh giá khác biệt giữa THA ẩn giấu với không THA, p4: đánh giá khác biệt giữa THA áo choàng trắng và $\mathrm{THA}$ ẩn giấu

Có sự khác biệt về độ tuổi trung bình và giới tính giữa các thể THA, cụ thể tuổi trung bình của nhóm THA ẩn giấu cao hớn so với hai nhóm còn lại và sự khác biệt có ý nghĩa thống kê. Nam giới có tỉ lệ THA ẩn giấu cao hơn so với nữ giới và so với các nhóm THA còn lại.

Bảng 3: Đặc điểm các yếu tố nguy cơ của các thể tăng huyểt áp (n=306)

\begin{tabular}{|c|c|c|c|c|c|c|c|}
\hline & \multirow{2}{*}{\multicolumn{3}{|c|}{ Phân loại tăng huyết áp }} & \multirow[b]{3}{*}{$\mathbf{p}_{1}$} & \multirow[b]{3}{*}{$\mathbf{p}_{2}$} & \multirow[b]{3}{*}{ p3 } & \multirow[b]{3}{*}{ p4 } \\
\hline & & & & & & & \\
\hline & $\begin{array}{c}\text { Không } \\
\text { THA } \\
(n=139)\end{array}$ & $\begin{array}{c}\text { THA } \\
\text { áo choàng trắng } \\
(n=92)\end{array}$ & $\begin{array}{l}\text { THA } \\
\text { ẩn giấu } \\
(\mathrm{n}=75)\end{array}$ & & & & \\
\hline \multicolumn{8}{|c|}{ Thời gian mắc đái tháo đường } \\
\hline$\geq 5$ năm & $48(34,5)$ & $48(52,1)$ & $44(58,7)$ & \multirow{2}{*}{0,001} & \multirow{2}{*}{0,008} & \multirow{2}{*}{0,001} & \multirow{2}{*}{0,401} \\
\hline$<5$ năm & $91(65,4)$ & $44(47,8)$ & $31(41,3)$ & & & & \\
\hline \multicolumn{8}{|c|}{ Tiền sử gia đình THA } \\
\hline Có & $46(33,1)$ & $55(59,8)$ & $55(73,3)$ & \multirow{2}{*}{$<0,001$} & \multirow{2}{*}{$<0,001$} & \multirow{2}{*}{$<0,001$} & \multirow{2}{*}{0,066} \\
\hline Không & $93(66,9)$ & $37(40,2)$ & $20(26,7)$ & & & & \\
\hline \multicolumn{8}{|c|}{ Tiền sử gia đình ĐTD } \\
\hline Có & $69(49,6)$ & $71(77,2)$ & $45(60,0)$ & \multirow{2}{*}{$<0,001$} & \multirow{2}{*}{$<0,001$} & \multirow{2}{*}{0,147} & \multirow{2}{*}{0,017} \\
\hline Không & $70(50,4)$ & $21(22,8)$ & $30(40,0)$ & & & & \\
\hline \multicolumn{8}{|c|}{ Hút thuốc lá } \\
\hline Có & $33(23,7)$ & $7(7,6)$ & $30(40,0)$ & \multirow{2}{*}{$<0,001$} & \multirow{2}{*}{0,002} & \multirow{2}{*}{0,013} & \multirow{2}{*}{$<0,001$} \\
\hline Không & $106(76,3)$ & $85(92,4)$ & $45(60,0)$ & & & & \\
\hline \multicolumn{8}{|c|}{ Uống rượu bia } \\
\hline Có & $13(9,4)$ & $2(2,2)$ & $9(12,0)$ & \multirow{2}{*}{0,042} & \multirow{2}{*}{0,030} & \multirow{2}{*}{0,543} & \multirow{2}{*}{0,011} \\
\hline Không & $126(90,6)$ & $90(97,8)$ & $66(88,0)$ & & & & \\
\hline \multicolumn{8}{|c|}{ Ān mặn } \\
\hline Có & $52(37,4)$ & $47(51,1)$ & $46(61,3)$ & \multirow{2}{*}{0,003} & \multirow{2}{*}{0,040} & \multirow{2}{*}{0,001} & 0,185 \\
\hline Không & $87(62,6)$ & $45(48,9)$ & $29(38,7)$ & & & & \\
\hline
\end{tabular}




\begin{tabular}{|c|c|c|c|c|c|c|c|}
\hline \multicolumn{8}{|c|}{ Tập thế dục } \\
\hline Có & $74(53,2)$ & $30(32,6)$ & $37(49,3)$ & 0.007 & 0.002 & 0.586 & 0.028 \\
\hline Không & $65(46,8)$ & $62(67,4)$ & $38(50,7)$ & 0,007 & 0,002 & 0,500 & \\
\hline
\end{tabular}

$\mathrm{p}_{1}$ : đánh giá khác biệt chung, $\mathrm{p}_{2}$ : đánh giá khác biệt giữa THA áo choàng trắng với không THA, $\mathrm{p}_{3}$ : đánh giá khác biệt giữa THA ẩn giấu với không THA, $\mathrm{p}_{4}$ : đánh giá khác biệt giữa THA áo choàng trắng và THA ẩn giấu

Các yễu tố như thời gian mắc bênh ĐTĐ típ 2, tiền sử gia đình THA, ĐTĐ, hút thuốc lá, uống rượu bia, ăn mặn và tập thể dục có mối liên quan chung với các thể THA.

Bảng 4: Đặc điểm sinh hóa của các thể huyết áp $(n=306)$

\begin{tabular}{|c|c|c|c|c|c|c|c|}
\hline & \multicolumn{3}{|c|}{ Phân loại tăng huyết áp } & \multirow[b]{2}{*}{$\mathbf{p}_{1}$} & \multirow[b]{2}{*}{$\mathbf{p}_{2}$} & \multirow[b]{2}{*}{$\mathbf{p}_{3}$} & \multirow[b]{2}{*}{$\mathbf{p}_{4}$} \\
\hline & $\begin{array}{c}\text { Không THA } \\
(n=139)\end{array}$ & $\begin{array}{c}\text { THA } \\
\text { áo choàng trắng } \\
(\mathrm{n}=92)\end{array}$ & $\begin{array}{l}\text { THA } \\
\text { ẩn giấu } \\
(\mathrm{n}=75)\end{array}$ & & & & \\
\hline $\begin{array}{l}\text { Đường huyết } \\
\text { đói (mmol/L) }\end{array}$ & $8,30 \pm 2,71$ & $8,46 \pm 2,65$ & $8,52 \pm 2,68$ & 0,819 & 0,888 & 0,836 & 0,991 \\
\hline $\begin{array}{c}\text { HbA1c >7\% } \\
(\%)\end{array}$ & $64(46,0)$ & $53(57,6)$ & $44(58,7)$ & 0,109 & 0,085 & 0,078 & 0,890 \\
\hline $\begin{array}{c}\text { Rối loạn lipid } \\
\text { máu }(\%)\end{array}$ & $115(82,7)$ & $76(82,6)$ & $61(81,3)$ & 0,965 & 0,980 & 0,798 & 0,831 \\
\hline
\end{tabular}

p1: đánh giá khác biệt chung, p2: đánh giá khác biệt giữa THA áo choàng trắng với không THA, p3: đánh giá khác biệt giữa THA ẩn giấu với không THA, p4: đánh giá khác biệt giữa THA áo choàng trắng và $T H A$ ẩn giấu

Nghiên cứu không có sự khác biệt về các thể HA theo các đặc điểm bất thường sinh hóa.

\section{BÀN LUẬN}

1. Các thể THA trên người bệnh ĐTĐ típ

2. Tỉ lệ mẫu nghiên cứu có $T H A$ áo choàng trắng là $30,1 \%$, cao hơn so với kết quả của Liana FF (2015) với $17,1,7 \%{ }^{(4)}$, nhưng lại thấp hơn nghiên cứu của Gorostidi M (2011) với 37,5\%(3). Đối với THA ẩn giấu, nghiên cứu của chúng tôi ghi nhận $24,5 \%$ mẫu nghiên cứu có thể THA này, tương đối gần với kết quả của Võ Thị Hà Hoa (2013) với $21,4 \%$ (2) và Tomiyama $M$ (2006) với $22,0 \%(7)$, thấp hơn so với Nguyễn Trần Tuyết Trinh (2013) là $57,8 \%{ }^{(1)}$. Sự khác biệt về các kêt quả nghiên cứu có thể do việc chọn đối tượng nghiên cứu và giới hạn cài đặt mức huyết áp cho máy đo huyết áp liển tục 24 giờ. Nhìn chung, THA ẩn giấu và THA áo choàng trắng chiếm tỉ lệ tương đối cao, cần được quan tâm chú ý trong quá trình điều trị, đặc biệt là trên các đối tượng có các yếu tố nguy cớ, cụ thể là người bệnh ĐTĐ típ 2. Ngoài ra, các nghiên cứu trên cũng đã chứng minh THA ẩn giấu và THA áo choàng trắng thường không được đánh giá đúng mức, từ đó gây nhiều tổn thương cho cơ quan đích ${ }^{(1)(2)}$. Điều này cho thấy, việc ứng dụng rộng rãi đo huyết áp liên tục 24 giờ là cần thiết cho việc phát hiện sớm các thể THA, từ đó, có liệu pháp điều trị phù hợp, giảm tác động bất lợi đến các cơ quan đích.

2. Các yếu tố nguy cơ của THA áo choàng trắng và THA ẩn giấu. Các yếu tố nguy cơ của bệnh lý THA đã được xác định rõ ràng thông qua các nghiên cứu trong và ngoài nước. Đặc biệt đối với người bệnh ĐTĐ, nguy cơ THA tăng gấp 2 lần và các tác động bất lợi cũng cao hơn so với người bệnh không ĐTĐ. Đối với nhóm người bệnh ĐTÐ típ 2, trọng lượng cơ thể, tuổi, giới, các tiền căn y khoa bản thân gia đình và các yếu tố về lối sống không lành mạnh góp phần đẩy mạnh tình trạng THA ở nhóm này.

Độ tuổi và giới tính là hai yếu tố không thay đổi được luôn chú trọng đánh giá trong THA ${ }^{(5)}$. Cụ thể, nam giới có tî lệ THA cao hơn so với nữ giới và độ tuổi càng cao thì tỉ lệ THA càng tăng. Trong nghiển cứu đang tiến hành, độ tuổi và giới tính có sự ảnh hưởng rõ rệt đến các thể THA: nhóm THA ẩn giấu có tuổi trung bình cao hơn so với nhóm không $T H A$, và nhóm THA áo choàng trắng. Bên cạnh đó, nam giới có tình trạng THA ẩn giấu cao hơn so với nữ giới, trong khi đó THA áo choàng trắng lại thường gặp ở nữ giới nhiều hơn. Xét về bản chất, THA áo choàng trắng chưa phải là bệnh THA thật sự, trong khi đó THA ẩn giấu được xem là bệnh lý nhưng chưa được phát hiện ra qua thăm khám thông thường. Điều này càng thể hiện rõ mối liên quan chặt chẽ giữa độ tuổi, giới tính và sự phát triển của bệnh lý THA. Việc sàng lọc THA, chủ yếu về THA ẩn giấu trên người cao tuổi và người bệnh ĐTÐ típ 2 cần được lưu ý.

ĐTÐ vứa là nguyên nhân vứa là hậu quả trực tiếp của THA. Thời gian mắc đái tháo đường 
cũng là môtt trong những yếu tố được chú trong đánh giá trên người bệnh có THA. Thời gian mắc bệnh ĐTĐ càng lâu thì khả năng mắc THA càng tăng(2)(5). Kết quả nghiên cứu cũng cho kết quả tương tự khi tỉ lệ nhóm THA áo choàng trắng và THA ẩn giấu ở nhóm những người mắc ĐTĐ típ 2 trên 5 năm cao hơn so với nhóm dưới 5 năm. Đối với THA áo choàng trắng, xảy ra chủ yếu là do tâm lý của người bênh lo lắng về tình trang sức khỏe của bản thân, thường gặp ở những người mới mắc bệnh. Đối với THA ẩn giấu, đây là tình trang bênh lý thât nhưng khó đánh giá trên lâm sàng, thường gặp ở người bệnh lớn tuổi và có mắc kèm ĐTĐ.

Tiền sử gia đình về THA và ĐTĐ được đánh giá là các yếu tố có liên quan đến tình trạng THA hiện tại của đối tượng nghiên cứu. Về cở chế tác động trực tiếp của vấn đề này chưa được đánh giá một cách chính xác. Các nghiên cứu chuyên sâu về di truyền cần được tiến hành để xác định mối liên quan thật sự giữa tiền căn gia đình THA, ĐTĐ và tình trạng bệnh lý của thế hệ tiếp theo.

Yếu tố về hành vi lối sống không lành mạnh như ăn mặn, uống rượu bia, hút thuốc lá, ít vận đông thể lực là các yểu tố có tác đông trực tiếp đến tình trạng $T H A, D \mathrm{~T}^{(6)}$. Sự tác động của các yếu tố này vừa ảnh hưởng trực tiếp, vừa thúc đẩy và tác động lẫn nhau lên tình trạng $\mathrm{THA}$, ĐTĐ, làm cho vấn đề này trở nên trầm trong hơn. Nghiên cứu đang tiến hành cũng ghi nhận kết quả tương tự so với các nghiên cứu trước đó về các yếu tố hành vi lối sống không lành manh và tác động thúc đẩy của các yếu tố này lên THA trên người bệnh ĐTĐ típ 2. Việc tư vấn, truyền thông giáo dục sức khỏe, hỗ trợ thay đổi hành vi, chuyển đổi từ các hành vi có hai thành các hành vi không có hại hoặc có lợi là cần thiết. Điều này một phần hỗ trợ phòng ngừa và làm giảm thiểu các tác động bất lợi của các hành vi không lành manh lên sức khỏe mối cá nhân.

Nghiên cứu ghi nhận không có sự khác biệt về đường huyết đói, các chỉ số về rối loạn mõ̃ máu giữa các nhóm THA. Điều này là do mẫu nghiên cứu của chúng tôi hoàn toàn là người bệnh ĐTÐ típ 2 , sự hiện diện của các yếu tố này hầu như là ở tất cả các đối tượng nghiên cứu.

Đối với THA áo choàng trắng, đây không phải là bệnh tăng huyết áp thật sự, tuy nhiên đây cũng không phải là một hiện tượng hoàn toàn lành tính. Các nghiên cứu ghi nhận người bệnh THA áo choàng trắng có nguy cơ tim mạch thấp hơn bệnh nhân THA thật sự nhưng cao hơn những người có huyêt áp hoàn toàn bình thường. Thông thường, bác sĩ điêu trị lẫn người bệnh thường ít để ý đến THA áo choàng trắng vì cho rằng đây là hiện tượng xảy ra do tâm lý người bệnh. Mặc dù vậy, việc đánh giá thể THA này cũng cần thiết cho các phương án điều trị, phòng ngừa THA trên đối tượng người bệnh ĐTĐ típ 2.

So với THA áo choàng trắng, THA ẩn giấu thường được chú ý đánh giá nhiều hơn vì tác đông của thể THA này là tương đương với THA thật sự nhưng lại khó phát hiện thông qua thăm khám lâm sàng thông thường. Các yếu tố nguy cơ của THA ẩn giấu không nằm ngoài các yếu tố nguy cơ của bệnh lý THA nói chung như thời gian mắc bệnh đái tháo đường, tăng cholesterol tăng triglycerid có liên quan đến THA ẩn giấu(2). Trong nghiên cứu của chúng tôi các yếu tố này chưa ghi nhận có mối liên quan có ý nghĩa thống kê. Sự khác biệt về kết quả nghiên cứu của chúng tôi là do khác biệt về đối tượng nghiên cứu. Nghiên cứu của tôi thực hiện trên đối tượng là người bệnh ĐTÐ típ 2, còn nghiên cứu của Võ Thị Hà Hoa lại thực hiện trên đối tượng là người bệnh THA. Mặc dù vậy, việc kiểm soát tốt các yểu tố kể trên là cần thiết, vì đây là các yếu tố không chỉ ảnh hưởng đến THA, ĐTĐ mà còn nhiều các bệnh lý khác.

\section{KẾT LUẬN}

Khi đánh giá THA trên người bệnh ĐTÐ típ 2, cần chú ý đánh giá về các thể THA áo choàng trắng và $T H A$ ẩn giấu vì các thể THA này khó phát hiện, phân biệt trên thăm khám lâm sàng thông thường. Việc phân định rõ các thể THA giúp nhà lâm sàng có phương hướng điêuu trị và phòng ngừa thích hợp, giảm thiểu các tác động bất lợi của các thể THA này lên cơ quan đích và sức khỏe chung của người bệnh.

\section{TÀI LIÊU THAM KHẢO}

1. Nguyễn Trân Tuyết Trinh (2014) "Khảo sát tình hình tăng huyết áp ẩn giấu trên bệnh nhân đái tháo đường típ 2". Tap chí Y hoc Tp.Hồ Chí Minh, 18 (1), tr.430-434

2. Võ Thi Hà Hoa, Đăng Văn Trí (2013) "Khảo sát đặc điểm biến thiên huyết áp ở bênh nhân tăng hưết áp ẩn giấu qua Holter huyết áp 24 giờ". Tạp chí Y học Tp. Hồ Chí Minh, 17 (3), tr.218-224

3. Gorostidi $M$, de la Sierra $A$, GonzálezAlbarrán 0, Segura J, de la Cruz JJ, Vinyoles E, Llisterri JL, Aranda $P$, Ruilope LM, Banegas JR (2011) "Abnormalities in ambulatory blood pressure monitoring in hypertensive patients with diabetes". Hypertens Res, 34 (11), pp.1185-9

4. Leiria LF, Severo MD, Ledur PS, Becker AD, Aquiar FM, Massierer D, Freitas VC, Schaan BD, Gus M (2015) "White coat effect and masked uncontrolled hvpertension in treated hypertensive-diabetic patients: Prevalence and 
tarqet orqan damage". Journal of diabetes, 7 (5), pp.699-707.

5. Mancia G, De Backer G, Dominiczak A, et al (2007) "2007 Guidelines for the management of arterial hypertension The Task Force for the Management of Arterial Hypertension of the European Sociaty of Hypertension (ESH) and of the European Society of Cardiology(ESC)". European Heart Journal, 28, pp.1462-1536.

6. Mazze RS, Robinson R, Simonson G, Idrogo
M, Simpson B, Kendall D, Bergenstal $\mathbf{R}$ (2004) "Undetected, uncontrolled blood pressure in type 2 diabetes: self-monitored blood pressure profiles". Blood Press, 13, pp.335-42.

7. Tomiyama M, Horio T, Yoshii M, Takiuchi $\mathbf{S}$ Kamide $K$, Nakamura $S$, Yoshihara $F$, Nakahama H, Inenaga T, Kawano Y (2006) "Masked hypertension and target organ damage in treated hypertensive patients". Am J Hypertens, 19 (9), pp.880-6.

\title{
VAT ĐÙI TRƯớC NGOÀI DANG CHÙM TRONG TAOO HİNH SAU PHẪU THUÂTT UNG THƯ KHOANG MIÊंNG: BÁO CÁO CA LÂM SÀNG VÀ HồI CỨU LẠI Y VĂN
}

\author{
Lê Văn Quảng ${ }^{1,2}$, Dương Mạnh Chiến ${ }^{1,2}$, \\ Ngô Quốc Duy ${ }^{1}$, Phan Văn Tân ${ }^{2}$, Ngô Xuân Quý1
}

\section{TÓM TẮT}

Ung thư khoang miệng là bênh ký ung thư phổ biến vùng đầu mặt cổ. Phẫu thuật là phương pháp điều trị chính ung thư khoang miệng. Khoang miệng sau cắt bỏ khối u thường để lại tổn khuyết lớn, khuyết hổng nhiều đơn vị tổ chức vùng khoang miệng như má, môi, lưỡi, sàn miệng..., nếu không có các phương pháp tạo hình phù hợp sẽ để lại hậu quả nặng nề cho chất lượng cuộc sống người bệnh. Phực hồi giải phẫu và chức năng các đớn vị giải phẫu tổn khuyết là ưu tiên hàng đầu của các phâuu thuật viên. Vạt đùi trước ngoài dạng chùm với nhiều ưu điểm nổi trội là lựa chọn hàng đâuu cho các tổn khuyết phức tạp vùng khoang miệng. Hiện nay, có rất ít báo cáo về tạo hình khuyết hổng lớn và phức tạp sau phẫu thuật khoang miệng bằng vat đùi trước ngoài dạng chừm. Báo cáo nhẳm mô tả đặc điểm tổn khuyết sau phẫu thuật ung thư khoang miệng và tạo hình bằng vạt đùi trước ngoài tự do dạng chùm thông qua ca lâm sàng.

Tư khóa: ung thư khoang miệng, vạt chùm đùi trước ngoài, vạt chùm.

\section{SUMMARY}

\section{UTILIZING THE CHIMERIC ANTERIORLATERAL THIGH FLAP FOR RECONSTRUCTION THE ORAL CAVITY} AFTER CANCER SURGERY: A CASE REPORT

Oral cancer is a common disease in head and neck cancer with a delayed clinical detection in situ. Surgery is the main method of treatment for oral cancer. Tumor resection left a large defect in face units such as cheek, lips, oral floor, tongue...

\footnotetext{
${ }^{1}$ Bệnh viện K Trung Ương

${ }^{2}$ Trường Đại học Y Hà Nội

Chịu trách nhiệm chính: Lê Văn Quảng

Email: Lequang@hmu.edu.vn

Ngày nhận bài: 17.12 .2020

Ngày phản biện khoa học: 20.01.2021

Ngày duyệt bài: 2.2.2021
}

Reconstructing these defects without appropriate strategy leading to unexpected results and regress the life quality of patients. Reconstruction the anatomy and funtion of face units is the priority of plastic surgeon. The chimeric anterolateal thigh free flap has several advantages to become the best material to reconstruct oral defects. Our report describe the characteristics of oral defect after tumor resection and reconstruction strategy with the chimeric anterolateal thigh free flap in a case report.

Keywords; oral cavity cancer, anterolateal thigh flap, chimeric flap

\section{I. ĐẶT VẤN ĐỀ}

Ung thư khoang miệng là một trong những bệnh lý ung thư phổ biến, chiếm tới $30-40 \%$ ung thư vừng đâu cổ. Phẫu thuật là phương pháp điều trị chính, với nguyên tắc phẫu thuật cắt u rộng rãi, nạo vét hạch hệ thống kết hợp với tạo hình lại khuyết hổng [1]. Việc phục hồi các khuyết hổng vùng miệng sau khi phẫu thuật cắt bỏ u cân đảm bảo cả về hình thái và chức năng. Trên thực tế, nhiều bệnh nhân khối u kích thước lớn, sau khi phẫu thuật để lại khuyết hổng lớn và phức tạp vùng khoang miệng nói riêng và đâu cổ nói chung, đặt ra nhiều thách thức cho các nhà phẫu thuật tạo hình khi lên kế hoạch điều trị. Trong những trường hợp đó, vạt đùi trước ngoài đăc biêt là vat chùm với đăc điểm cấu tao nhiều thành phân, khả năng thiết kế che phủ đổng thời nhiều bộ phận là một chất liệu thích hợp để tạo hình lại khuyết hổng. Vạt đưi trước ngoài được Song YG và cộng sự mô tả lân đâu tiên vào năm 1984 và ngày càng được ứng dụng rộng rãi. Một hình thức sử dụng đặc biệt của vạt đùi trước ngoài là vạt chùm (chimeric flap). Vạt chùm là vạt gồm nhiều vạt thành phân, trong đó mỗi vạt được cấp máu bởi một nguồn mạch riêng nhưng 